\title{
Impactos decorrentes da implantação de pólos geradores de viagens na estrutura espacial das cidades
}

\author{
Erika Cristine Kneib ${ }^{1}$; Paulo Cesar Marques da Silva²; \\ Licinio da Silva Portugal ${ }^{3}$
}

\begin{abstract}
Resumo: Em meio às alterações que ocorrem nas cidades, com ênfase no uso e ocupação do solo e nos deslocamentos, este trabalho tem por objetivo avaliar os possíveis impactos decorrentes da implantação de Polos Geradores de Viagens (PGVs) na estrutura espacial das cidades, conformada pelo conjunto de centros e subcentros urbanos. Como conclusão, a partir do método desenvolvido, corroborase a relação entre os PGVs e os impactos decorrentes destes na estrutura espacial da cidade objeto do estudo. Assim como, identificamse as atividades que mais contribuem para tal relação.
\end{abstract}

\begin{abstract}
Among the changes that take place in the cities, especially those related to trips and to land use and occupation, this paper aims at assessing the possible impacts caused by the implantation of trip generating developments in their spatial structure, shaped by urban centres and subcentres. In conclusion, from the method developed in the work, the relationship is confirmed between trip generating developments and their impacts on the spatial structure of the city studied, as well as the activities that most contribute to that relationship are identified.
\end{abstract}

\section{INTRODUÇÃO}

As cidades são organismos dinâmicos, com notórias alterações ao longo do tempo, inclusive em sua estrutura espacial, sendo o transporte um elemento chave nessas transformações. $\mathrm{O}$ transporte tem uma função na organização e na estruturação do espaço urbano, uma vez que o crescimento e desenvolvimento das cidades ocorreram fortemente vinculados aos sistemas de transporte.

No Brasil, a partir, principalmente, de 1980, a estrutura espacial urbana sofre uma grande transformação de monocêntrica para policêntrica, passando de um centro para uma rede composta por centro e subcentros - encetando uma nova abordagem relativa ao espaço urbano (Kneib, 2008). Nesta mesma época, a partir de 1980, grandes empreendimentos começam a entrar em operação, conferindo ao espaço urbano diversos impactos negativos advindos do grande volume de viagens, o que principiou a necessidade de estudar e avaliar os impactos de tais empreendimentos, denominados então de Pólos Geradores de Tráfego. Entretanto, com a evolução de tais estudos, verificou-se que os impactos advindos de tais empreendimentos eram mais abrangentes, ultrapassavam o âmbito do tráfego, e deveriam ser analisados inclusive quanto aos impactos no desenvolvimento socioeconômico e na qualida-

\footnotetext{
${ }^{1}$ Erika Cristine Kneib, Universidade Federal de Goiás, Goiânia, GO, Brasil. (e-mail: erikakneib@terra.com.br).

${ }^{2}$ Paulo Cesar Marques da Silva, Universidade de Brasília, Brasília, DF, Brasil. (e-mail: pcmsilva@unb.br).

${ }^{3}$ Licinio da Silva Portugal, Universidade Federal do Rio de Janeiro, Rio de Janeiro, RJ, Brasil. (e-mail: licinio@pet.coppe.ufrj.br).
}

Manuscrito recebido em 21/1/2010 e aprovado para publicação em 12/3/2010. Este artigo é parte de TRANSPORTES, volume XVIII, número 1, março de 2010. 2237-1346 (online). de de vida da população (REDPGV, 2010) e na formação de centralidades (Kneib, 2004). Assim, na tentativa de um conceito que corroborasse a consideração dos impactos mais abrangentes, adotou-se a denominação de Polos Geradores de Viagens - PGVs.

Neste contexto, o presente trabalho propõe-se a contribuir dentro dessa abordagem, mais abrangente, sobre os impactos relacionados aos PGVs, com a análise da influência dos PGVs na estrutura espacial das cidades, ao ponderar a influência de tais empreendimentos em subcentros de um município específico, Manaus. Para tal, desenvolve-se um procedimento metodológico de análise, composto por sete etapas, que permite, para os casos estudados, avaliar a relevância dos PGVs na conformação das centralidades urbanas.

\section{A ESTRUTURA ESPACIAL URBANA E O SISTEMA DE TRANSPORTES}

São diversos os estudos e referências que procuram abordar a questão da estrutura espacial das cidades. Conforme abordagem que segue, essa estrutura define-se a partir de elementos físicos e funcionais, centralidades, nós, ou ainda processos relacionados a tais elementos. Segundo (França, 2004), por exemplo, a estrutura espacial urbana compreende a estrutura física (espaços públicos abertos e formas construídas) e a funcional (atividades) que, ao se interagirem mutuamente, geram fluxos e movimentos, possibilitando a geração de novas estruturas, tornando a cidade um sistema configuracional dinâmico.

Rochefort (1998) ressalta que a unidade de organização da cidade é constituída pelo conjunto de centros necessários para fornecer a totalidade dos serviços requisitados pelas atividades e pela população. Segundo 
Tabela 1. Elementos ou processos que conformam o espaço urbano

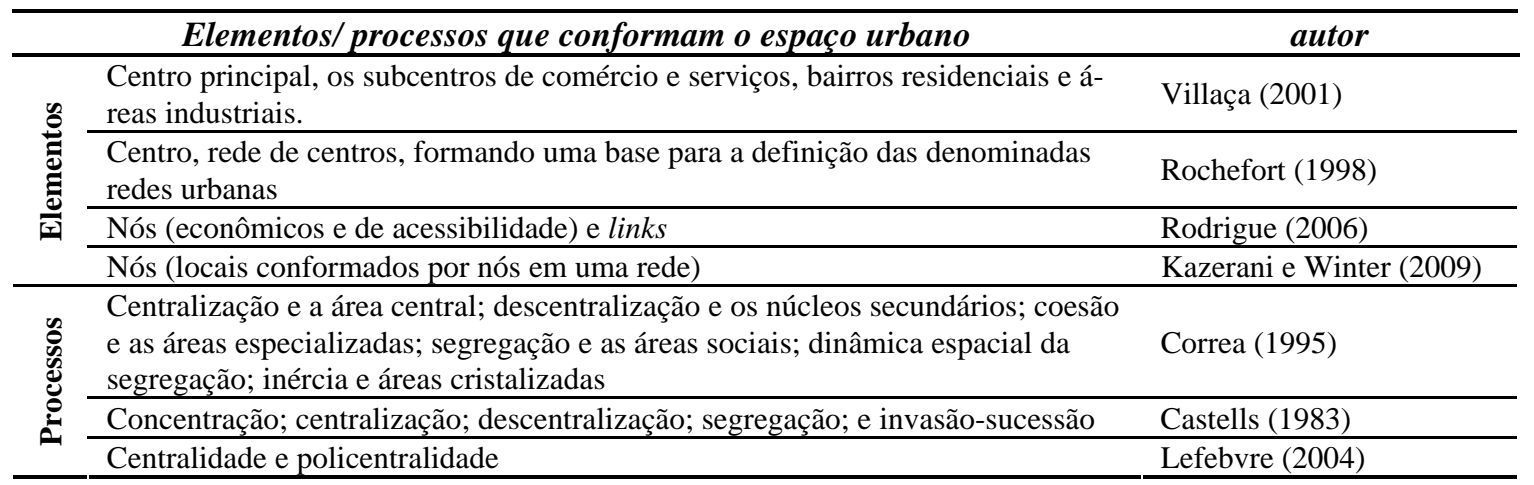

o autor, a organização do espaço resulta da localização dos diferentes centros. $\mathrm{E}$ em virtude da diferença entre os centros, a geografia leva a definição de formas de interdependência entre os centros, o que permite a passagem de uma noção de centro para uma noção de rede de centros, formando uma base para a definição das denominadas redes urbanas, ou ainda sistema urbano de um espaço.

A Tabela 1 procura sintetizar os elementos ou processos que conformam o espaço urbano, segundo a visão de autores pesquisados. Cabe enfatizar a importância dos centros e subcentros, como elementos, ou inseridos em processos de conformação da estrutura espacial urbana.

Sobre a relação entre a estrutura espacial urbana e o sistema de transportes, cabe citar os estudos de John S. Adams, que identificou ciclos construtivos nas cidades americanas. Cada um desses ciclos estava relacionado a mudanças na tecnologia dos transportes, conformando padrões distintos na organização espacial intra-urbana de crescimento concêntrico e expansão radial (Taaffe et al., 1996).

Com relação a estudos nacionais, especificamente sobre a centralidade no contexto dos Planos Diretores, o Ministério das Cidades (2004) relaciona a formação e a consolidação dos subcentros urbanos - a multicentralidade (ou policentralidade) - à eficiência e organização das cidades, pois a policentralidade é capaz de proporcionar aos cidadãos o acesso aos serviços essenciais, dispensando-se deslocamentos motorizados, realizando pequenas viagens a pé ou de bicicleta; ou ainda favorece a possibilidade de acessá-los pelos modos coletivos de transporte. Segundo o estudo, a multicentralidade contribui para diminuir o número de viagens motorizadas.

Diesendorf (2000) ressalta a policentralidade como uma das características das cidades que buscam a sustentabilidade. Como características dos subcentros, o autor destaca: o mix de usos do solo; o acesso da comunidade a determinadas atividades, como escolas, bibliotecas e creches; a compacidade, ou a facilidade de alcançar as principais atividades pelos modos não motorizados - a pé ou bicicleta; acesso restrito aos au- tomóveis; a presença de, pelo menos, uma estação de transporte público (trem); a existência de espaços públicos.

Segundo Schwanwn et al. (2001), os estudos sobre policentralidade estão diretamente relacionados às questões dos padrões de viagem, uma vez que a forma urbana pode impactar diretamente o tempo e distância dos deslocamentos pendulares. Como resultado, os padrões das viagens diárias tornaram-se tangenciais e não mais radiais, em grande parte das áreas metropolitanas. Esse resultado gerou dois comportamentos de viagens a partir da policentralidade:

i) conforme alguns trabalhos, a policentralidade tende a diminuir o tempo e a distância das viagens pendulares (Levinson e Kumar, 1994; Gordon e Richardson, 1996; Schwanwn et al. 2001, Aguilera e Mignot, 2004; McMillen, 2004);

ii) segundo outros, o número de deslocamentos individuais motorizados tende a aumentar, sendo a policentralidade negativa (Cevero, 1996; Ewing, 1997). Isso se dá caso a infra-estrutura de transporte coletivo e o incentivo aos modos não motorizados não acompanhem as novas centralidades (Schwanwn et al. 2001; Aguilera e Mignot, 2004).

Ao se relacionar PGVs e subcentros, observa-se que a principal característica dos PGVs é o impacto advindo da geração de viagens. Nesse sentido, pode-se estabelecer uma comparação entre os estudos citados anteriormente:

i) de acordo com os trabalhos que afirmam que a policentralidade tende a diminuir o tempo e a distância das viagens pendulares, a conformação de uma nova centralidade advinda da implantação de um PGV seria benéfica à estrutura da cidade;

ii) porém, segundo os demais trabalhos, pode-se estimar que caso a implantação de um PGV leve à ascensão de um novo subcentro e caso a infra-estrutura de transporte coletivo e o incentivo aos modos não motorizados não acompanhem a nova centralidade (Schwanwn et al. 2001; Aguilera e Mignot, 2004), isso poderia impactar negativamente, com o aumento do número de deslocamentos individuais motorizados, agravando ainda mais os impactos negativos decorren- 
tes da implantação do citado polo.

Tais abordagens ratificam mais uma vez a importância da análise dos subcentros, assim como dos elementos que contribuem para sua formação, de maneira a tornar a policentralidade positiva para o espaço; e possibilitar a adoção de políticas específicas segundo a vocação ou potencialidade do subcentro, com relação à sua acessibilidade e à mobilidade das pessoas.

\section{PGVS E A ESTRUTURA ESPACIAL URBANA}

São diversas as fontes bibliográficas existentes que denominam empreendimentos que geram um grande número de viagens como Polos Geradores de Tráfego (PGTs). Até o ano de 2003, esse conceito foi bastante trabalhado com relação aos impactos no trânsito e na circulação. Como exemplos, apontam-se os estudos da Companhia de Engenharia de Tráfego de São Paulo (CET), de 1982; de Grando, de 1986; do Departamento Nacional de Trânsito (DENATRAN), de 2001; e de Portugal e Goldner, de 2003.

Os estudos afetos ao tema contribuíram para a evolução desse conceito, que deixou de considerar apenas o tráfego (individual) motorizado gerado pelo empreendimento, passando a considerar as viagens em geral; além dos impactos relacionados ao polo não mais somente nos sistemas viário e de transportes, como também no desenvolvimento socioeconômico (Kneib et al., 2009). Como principais estudos, destacam-se os conceitos de Empreendimentos Geradores de Viagens e Centros Geradores de Viagens (Kneib, 2004) e de Polos Geradores de Viagens - PGVs, da Rede Ibero Americana de Estudos de Polos Geradores de Viagens (2005).

Assim, posteriormente ao ano de 2005, esse novo conceito ganhou forças e, na literatura nacional relacionada ao planejamento dos transportes, os grandes empreendimentos urbanos passaram a ser denominados Polos Geradores de Viagens - PGVs. Os PGVs são descritos como equipamentos potenciais geradores de impactos nos sistemas viários e de transportes (congestionamentos, acidentes e naturais repercussões no ambiente) como também no desenvolvimento socioeconômico e na qualidade de vida da população (REDPGV, 2010). A adoção dessa denominação, assim como seu conceito, mostra uma evolução dos estudos e da consideração dos impactos gerador por esse tipo de empreendimento.

O trabalho de Kneib (2004) destaca a grande relação entre tais empreendimentos e as centralidades urbanas. Segundo o trabalho, o ferramental teóricoconceitual dos centros urbanos aplica-se para caracterizar tais empreendimentos. E ao aplicar tal ferramental aos PGVs, o trabalho descreve, simplificadamente, o seguinte processo análogo ao ocorrido em áreas centrais: a implantação e operação do empreendimento atribui características de centralidade à área; atrai um grande número de pessoas, gerando um determinado número de viagens; altera os padrões de uso e ocupação do solo, atraindo novas atividades e novas construções; com o aumento da demanda por áreas seus terrenos são valorizados, atraindo mais atividades, mais construções, e conseqüentemente um número adicional de viagens, formando um processo cíclico. Neste processo, é destacada a relevância da acessibilidade no processo de ascensão ou degradação da nova centralidade.

O trabalho introduz o conceito de Centros Geradores de Viagens (CGVs), definindo-os como atividades urbanas de grande porte, que atribuem características de centralidade à sua área de influência e impactam o ambiente urbano por meio de geração de viagens, podendo causar alterações significativas nos padrões de uso, ocupação e valorização do solo em sua área de influência imediata (Kneib, 2004), e comprova a aplicabilidade desse conceito para um caso específico. Esta abordagem procurou complementar a definição inicial de PGTs (Polos Geradores de Tráfego), ao contribuir com a necessidade de destacar que a análise de tais polos deveria ser mais abrangente - englobando inclusive impactos na estrutura espacial das cidades - e não apenas focada no tráfego. Aspectos contemplados, posteriormente, em abordagens que passaram a considerá-los como Polos Geradores de Viagens.

Em resumo, com relação aos PGVs e à estrutura espacial das cidades, cabe destacar que a implantação de grandes empreendimentos impacta toda a estrutura urbana da área em que tais empreendimentos são inseridos, podendo contribuir para a formação de novas centralidades. Neste contexto, o presente trabalho propõe-se a estudar, quantitativamente, no caso de um município específico, a influência dos PGVs na conformação das centralidades e, por conseguinte, a influência desses empreendimentos na alteração da estrutura espacial urbana. No âmbito de análise de PGVs e centralidades, são raros os estudos que procuraram avaliar tal relação, principalmente de forma quantitativa.

\section{PROCEDIMENTO METODOLÓGICO PROPOSTO}

Depois de abordada a relação entre a estrutura espacial das cidades e o transporte, com ênfase na geração de viagens, assim como os possíveis impactos decorrentes da implantação de PGVs na estrutura espacial das cidades, esse item apresenta a metodologia desenvolvida para a análise da relevância dos PGVs na conformação das centralidades urbanas. No item seguinte, 


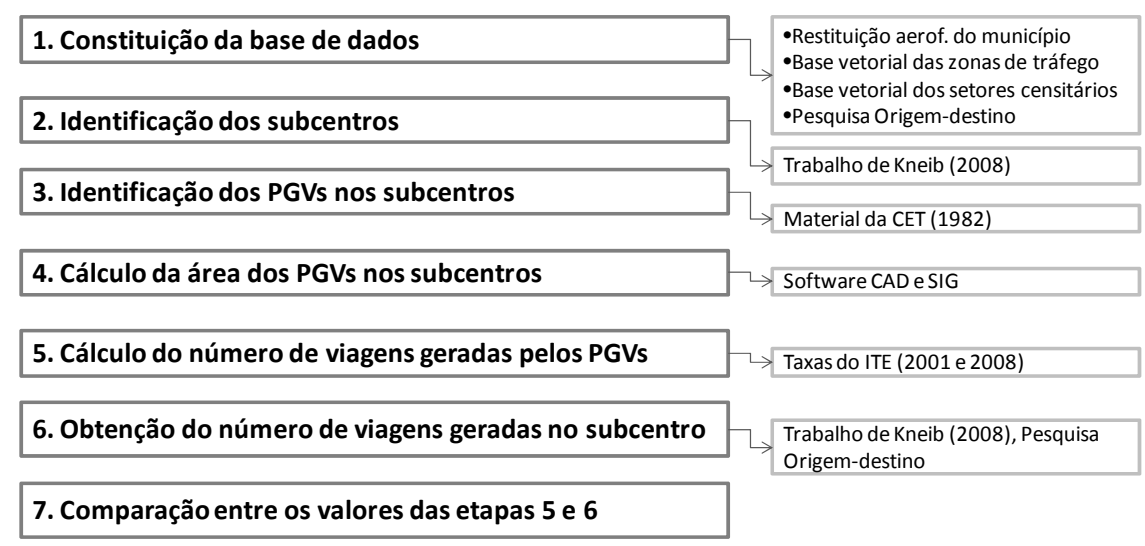

Figura 1. Procedimento metodológico adotado

tal procedimento é aplicado em um estudo de caso específico, realizado no município de Manaus. Destarte, como metodologia de trabalho, adotou-se o procedimento composto por sete etapas, ilustrado na Figura 1.

Com relação à identificação dos subcentros urbanos, são diversas as metodologias existentes (como Giuliano e Small, 1991; Anderson e Bogart, 2001; Pan e Ma, 2006) que baseiam sua identificação na variável densidade e número de empregos. Neste trabalho, para a identificação de subcentros urbanos, adotaram-se o conceito e a metodologia desenvolvida por Kneib (2008), que define subcentro como uma área com número de viagens geradas significantemente maior do que as áreas vizinhas. Para medir tal significância, o estudo utiliza estatística espacial. Segundo a autora, a variável geração de viagens consegue refletir as características inerentes às áreas centrais, independente de seu uso. Assim, também foram adotados os subcentros identificados pelo trabalho de Kneib (2008) para a cidade objeto do estudo de caso, Manaus.

Para a categorização de empreendimentos como PGVs, foram usados critérios baseados nas classificações da CET (1982), a partir dos quais foram focados empreendimentos não domiciliares. Isso se deve a uma limitação metodológica, uma vez que os dados de domicílios utilizados são provenientes de Setores Censitários e estão agrupados, impossibilitando sua classificação nos critérios de PGVs estabelecidos que, segundo a CET (1982), são conjuntos residenciais acima de 200 unidades. Para o cálculo das viagens geradas para PGVs e demais usos, adotaram-se as taxas de geração de viagens do ITE (2001 e 2008), conforme Tabela 2.

\section{ESTUDO DE CASO}

Com base na metodologia apresentada no item 4, este trabalho pretende examinar, quantitativamente, a existência de PGVs e seu porte, quando inseridos nos subcentros identificados, de forma a verificar se o conceito desenvolvido por Kneib (2004) é aplicável ao município de Manaus. Para tal, mede-se o percentual do número de viagens geradas em cinco zonas de tráfego, especificamente por empreendimentos classificados como PGVs, com foco em usos não domiciliares, com relação às viagens totais dos subcentros identificados.

Sobre Manaus, cabe destacar que está localizada no estado do Amazonas, na região Norte do Brasil. Possui uma população de 1.738.641 habitantes (IBGE, 2009) e constitui uma das dez maiores cidades do Brasil. Seu crescimento, a partir do ano de 2000, foi bastante acelerado e a infra-estrutura para o transporte não conseguiu acompanhar esse crescimento no mesmo ritmo (Prefeitura de Manaus e Ceftru, 2006).

A Figura 2 apresenta os subcentros identificados para a Zona de Tráfego 120, enquanto o Quadro 1 apresenta os PGVs presentes nos subcentros identificados. A Figura 3 apresenta o número de viagens geradas por PGVs com relação às viagens totais dos subcentros 1 , 2,3 e 4.

Observa-se, na Figura 3, que todos os subcentros apresentaram mais de $60 \%$ de suas viagens geradas

Tabela 2. Taxas de geração de viagens diárias para PGVs e demais usos com base em taxas do ITE (2001 e 2008)

\begin{tabular}{lcc}
\hline \multicolumn{1}{c}{ Uso } & Taxa de geração de viagens & Unidade \\
\hline Residência & 9,5000 & $\mathrm{un}$ \\
\hline Saúde & 0,3678 & $\mathrm{~m}^{2}$ \\
\hline Educação & 0,2508 & $\mathrm{~m}^{2}$ \\
\hline Público/Institucional & 0,7420 & $\mathrm{~m}^{2}$ \\
\hline Comércio/Serviço & 0,7549 & $\mathrm{~m}^{2}$ \\
\hline Indústria & 0,0750 & $\mathrm{~m}^{2}$ \\
\hline Lazer & 0,1845 & $\mathrm{~m}^{2}$ \\
\hline Terminais de Transporte & 0,0920 & $\mathrm{~m}^{2}$ \\
\hline
\end{tabular}




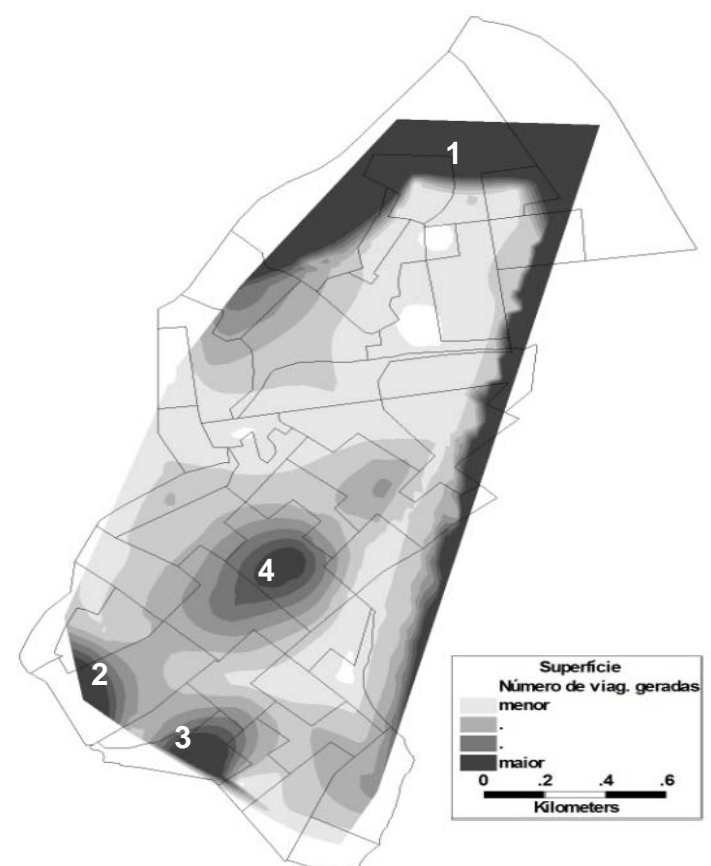

Figura 2. Subcentros identificados para a Zona de Tráfego 120

por empreendimentos classificados como PGVs, o que confirma a abordagem presente no trabalho de Kneib (2004) para a ZT 120, na qual os PGVs contribuem sobremaneira para a existência e/ou consolidação dos respectivos subcentros nessa zona.
Ainda com relação aos usos dos subcentros da ZT 120, destaca-se que, no subcentro 1, com relação ao percentual de viagens de PGVs geradas por atividade, predomina o uso institucional, com $67 \%$; no subcentro 2 também predomina o uso institucional, com 57\%; no subcentro 3 predomina o uso comercial, com 73\%; enquanto no subcentro 4 , o uso predominante é o institucional, com $66 \%$. Tais dados possibilitam identificar quais usos desenvolvidos como PGVs foram mais relevantes para a formação dos subcentros dessa zona.

Analogamente à zona 120, foram feitas análises para as zonas 105, 115, 504 e 406, apresentadas nas Figuras 4 a 7 , respectivamente.

Para facilitar o entendimento, foram elaborados gráficos que procuram demonstrar a relação entre as viagens totais dos subcentros e as viagens decorrentes de PGVs, conforme visualização nas Figuras 8 a 11, segundo as quais é possível observar:

- Com relação à zona 105 - observa-se, na Figura 8 , que o subcentro 2 apresenta mais de $60 \%$ de suas viagens geradas por empreendimentos classificados como PGVs, o que também confirma o trabalho de Kneib (2004), para esse caso. Sobre o percentual de viagens de PGVs geradas por atividade, predomina o uso institucional, com 46\%. Já para o subcentro 1, não foi ve-

Quadro 1: PGVs presentes nos subcentros identificados na Zona 120

\begin{tabular}{|c|c|c|c|c|c|c|c|}
\hline \multicolumn{4}{|c|}{ Subcentro 1 - PGVs } & \multicolumn{4}{|c|}{ Subcentro 3 - PGVs } \\
\hline Empreendimento & Uso & $\mathrm{m} 2$ & viagens geradas & Empreendimento & Uso & m2 & viagens geradas \\
\hline Companhia CPRM & institucional & 3400 & 2522.65 & Comércio & comercial & 9390 & 7088.26 \\
\hline Igreja & institucional & 3110 & 2307.49 & & & & \\
\hline Jornal & institucional & 4175 & 3097.67 & Viagens totais de $\mathrm{PC}$ & jVs & & 7088.26 \\
\hline Incra & institucional & 3000 & 2225.87 & $\%$ viagens do subce & ntro & & 73.45 \\
\hline INPA & institucional & 29270 & 21717.07 & & & & \\
\hline Escola & educacional & 5550 & 1391.94 & & & & \\
\hline Escola & educacional & 2400 & 601.92 & & & & \\
\hline Campo de futebol & clube/lazer & 1900 & 350.55 & & & & \\
\hline Campo de futebol & clube/lazer & 4780 & 881.91 & & & & \\
\hline Quadra de esporte & clube/lazer & 700 & 129.15 & & & & \\
\hline Clube & clube/lazer & 1000 & 184.50 & & & & \\
\hline \multirow{2}{*}{\multicolumn{3}{|c|}{$\begin{array}{l}\text { Viagens totais de PGVs } \\
\% \text { viagens do subcentro }\end{array}$}} & 35410.72 & & & & \\
\hline & & & 62.71 & & & & \\
\hline \multicolumn{4}{|c|}{ Subcentro 2 - PGVs } & \multicolumn{4}{|c|}{ Subcentro 4 - PGVs } \\
\hline Empreendimento & Uso & $\mathrm{m} 2$ & viagens geradas & Empreendimento & Uso & $\mathrm{m} 2$ & viagens geradas \\
\hline Corpo Bomb & institucional & 4131 & 3065.02 & Polícia Militar & instituciona & 9390 & 4567.00 \\
\hline Polícia Militar & institucional & 3000 & 2225.87 & & & & \\
\hline Colégio & educacional & 3540 & 887.83 & \multicolumn{3}{|c|}{\begin{tabular}{|l} 
Viagens totais de PGVs \\
\end{tabular}} & 4567.00 \\
\hline \multirow{2}{*}{\multicolumn{4}{|c|}{ Viagens totais de PGVs }} & \multicolumn{3}{|c|}{$\%$ viagens do subcentro } & 66.15 \\
\hline & $\overline{\mathrm{GVS}}$ & & 6178.72 & & & & \\
\hline \multicolumn{3}{|c|}{$\%$ viagens do subcentro } & 69.15 & & & & \\
\hline
\end{tabular}

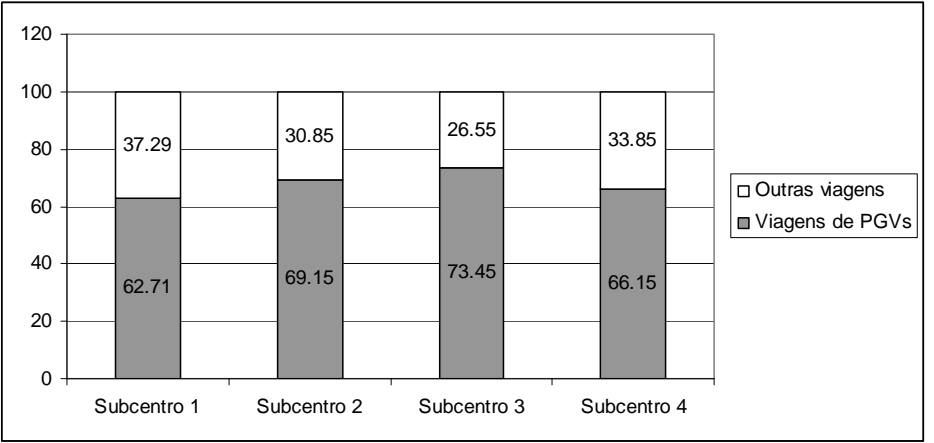

Figura 3. Número de viagens, em percentual, geradas por PGVs, com relação às viagens totais dos subcentros identificados para a ZT 120 


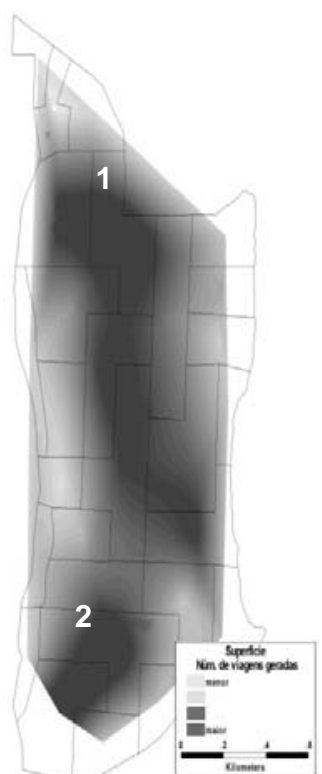

Figura 4. Subcentros identificados para a Zona de Tráfego 105

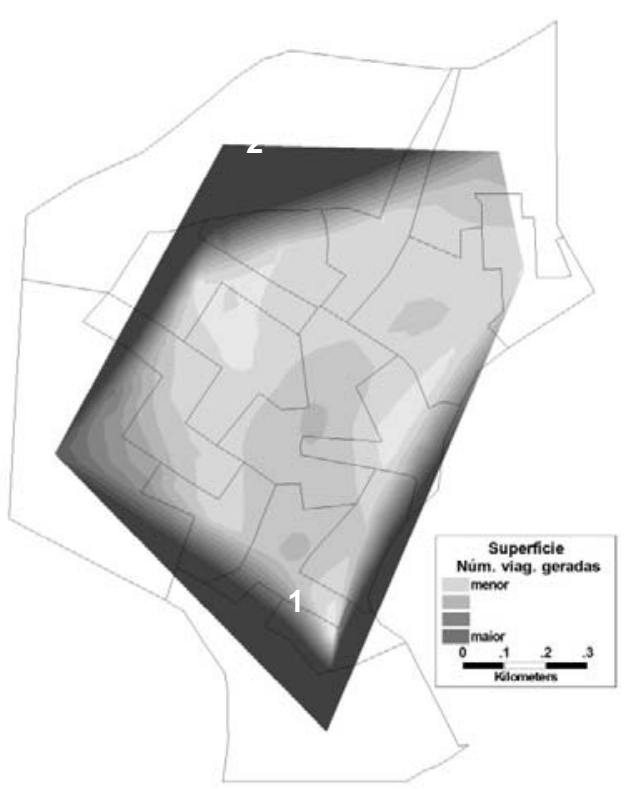

Figura 5. Subcentros identificados para a Zona de Tráfego 115

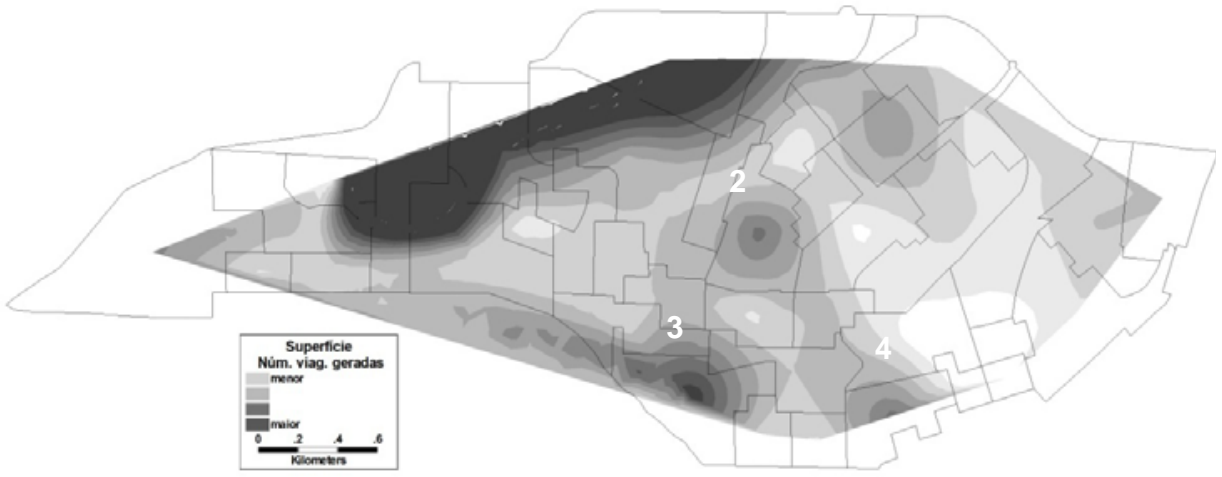

Figura 6. Subcentros identificados para a Zona de Tráfego 504

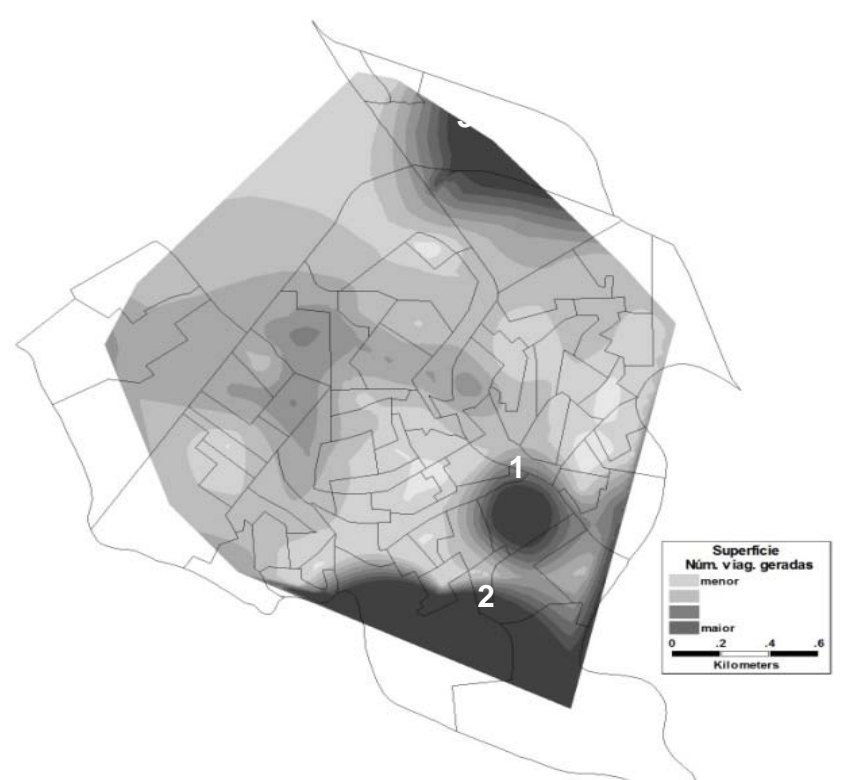

Figura 7. Subcentros identificados para a Zona de Tráfego 406

rificada tal observação, uma vez que este apresentou apenas $24 \%$ das viagens geradas por PGVs;

- Com relação à zona 115 - observa-se, na Figura 9, que ambos os subcentros apresentam mais de $70 \%$ de suas viagens geradas por empreendi- mentos classificados como PGVs, o que confirma o trabalho de Kneib (2004), para o caso da ZT 115. O subcentro 1 apresenta $60 \%$ das viagens de PGVs geradas pela atividade saúde, enquanto o uso predominante no subcentro 2 é o institucional, com 51\%; 
- Com relação à zona 504 - observa-se, na Figura 10 , que os subcentros não apresentaram influências significativas de PGVs. Entretanto, devido à limitação metodológica para a análise de PGVs domiciliares, apresentada no item 4, tal análise era esperada, uma vez que todos os subcentros apresentaram grande número de viagens geradas pelo uso domiciliar: subcentro 1 , com $37 \%$ das viagens geradas pelo uso domiciliar; subcentro 2, com 95\% das viagens; subcentro 3, com $50 \%$, e subcentro 4 , com $71 \%$. Tais dados ressaltam que, apesar desta metodologia não enfocar subcentros domiciliares, estes se mostraram relevantes no processo de conformação da estrutura espacial urbana;

- Com relação à zona 406 - observa-se, na Figura 11 , que os subcentros apresentam mais de $60 \%$ de suas viagens geradas por empreendimentos classificados como PGVs, o que também confirma o trabalho de Kneib (2004), para o caso da ZT 406. Sobre o percentual de viagens de PGVs geradas por atividade, predomina, no subcentro 1, o uso comercial, com 55\%; no subcentro 2, o uso institucional, com $77 \%$; no subcentro 3, também o uso institucional, com $67 \%$.

Com base nos dados analisados, sobre a influência dos PGVs na formação das centralidades, observa-se que dos 15 subcentros analisados, 10 apresentaram números de viagens geradas por PGVs superiores a $60 \%$, o que corrobora o conceito de Kneib (2004) para

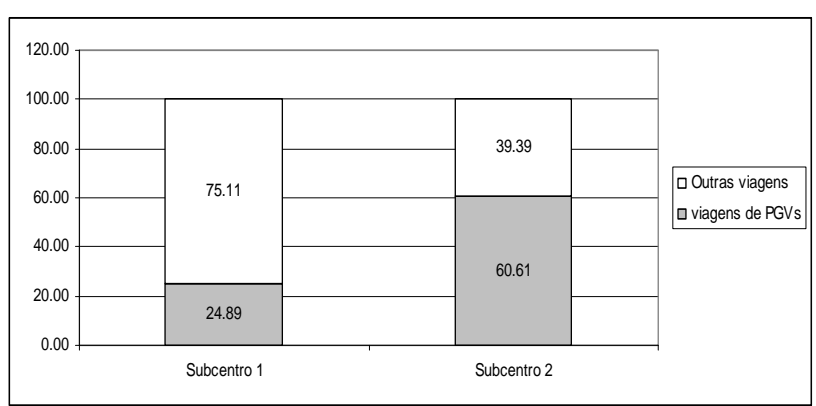

Figura 8. Número de viagens geradas por PGVs, em percentual, com relação às viagens totais dos subcentros identificados para a ZT 105

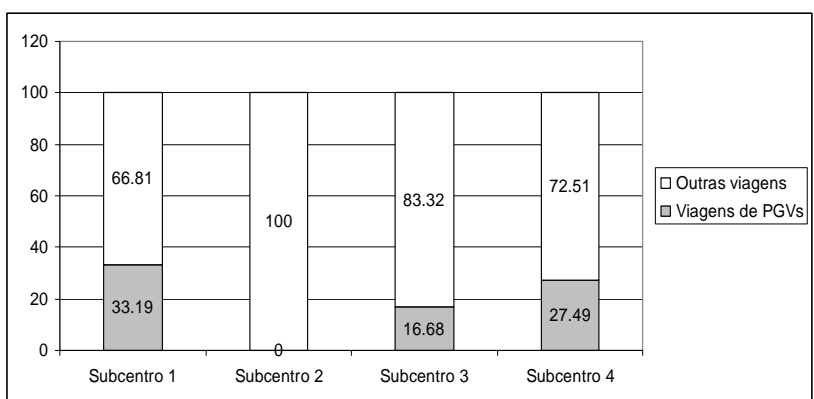

Figura 10. Número de viagens geradas por PGVs, em percentual, com relação às viagens totais dos subcentros identificados para a ZT 504 esses casos. Com relação aos usos e atividades que mais geram impactos na formação e consolidação de centralidades, nos 15 casos estudados, merece destaque o uso institucional, com 7 subcentros que tiveram a predominância de viagens geradas por esse uso; seguido do uso comercial, com 4; do uso domiciliar, com 3 e, por fim, do uso saúde, com 1 . Ou seja, em conformidade com os casos estudados, PGVs de usos institucionais e comerciais mostraram-se os mais relevantes na alteração dessa estrutura espacial urbana.

Sobre a importância dos PGVs na conformação de centralidades, cabe ressaltar que um dos principais objetivos do desenvolvimento de teorias e estudos relativos à função e à estrutura espacial urbana consiste em elaborar técnicas de previsão e estimativas, especialmente para uma avaliação das alternativas de atuação pública. A possibilidade de avaliação de alternativas pode proporcionar um valioso guia para a formação de diretrizes de atuação dos gestores de determinado espaço urbano.

Destarte, com relação à formação de diretrizes de atuação dos gestores de determinado espaço urbano e com base nos dados apresentados, é possível fazer as seguintes considerações: ao se permitir a construção de determinados empreendimentos na cidade, o processo de planejamento urbano deve considerar a possibilidade de que a implantação de tais empreendimentos inicie a conformação de uma nova centralidade, o que vai acarretar em um processo de alteração de uso, ocupação, valorização do solo e atração de fluxos e novas atividades. É notório, ainda, que tal processo

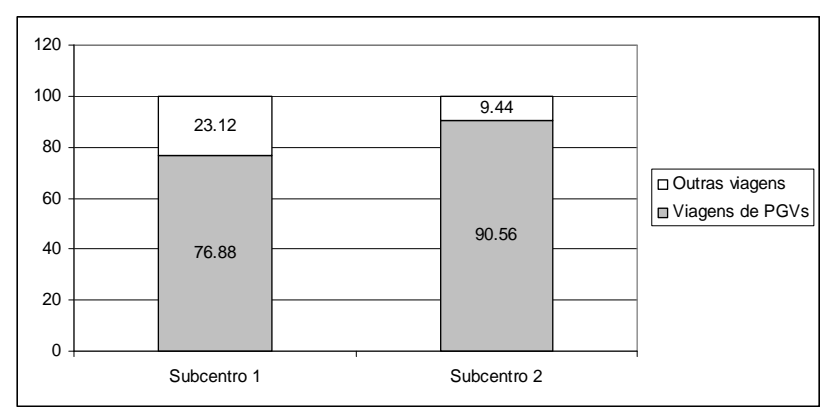

Figura 9. Número de viagens geradas por PGVs, em percentual, com relação às viagens totais dos subcentros identificados para a ZT 115

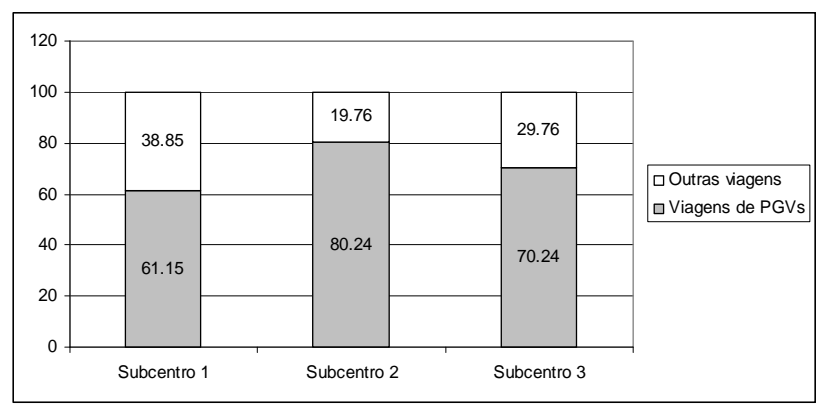

Figura 11. Número de viagens geradas por PGVs, em percentual, com relação às viagens totais dos subcentros identificados para a ZT 406 
impactará a estrutura espacial urbana da cidade em questão.

Resta saber se a estrutura espacial da cidade: (i) comportará este novo subcentro, se ele é desejável e deve ser potencializado; (ii) ou se ele não é desejável e devem ser discutidas medidas para frear seu crescimento.

Ainda com relação à formação de diretrizes de atuação, segundo estudos, a policentralidade contribui para diminuir o número de viagens motorizadas, pois é capaz de proporcionar aos cidadãos o acesso aos serviços essenciais por modos coletivos e não motorizados. Assim, corroborando essa assertiva, destaca-se que a implantação de PGVs e a conformação de novas centralidades, quando desejadas e planejadas, podem contribuir para a reversão da matriz modal atual no Brasil ao incentivar, nesses novos subcentros, modos coletivos e não motorizados de transporte.

\section{CONSIDERAÇÕES FINAIS}

Este trabalho buscou avaliar a influência dos PGVs na estrutura espacial das cidades, a partir de uma metodologia desenvolvida para a análise da relevância dos PGVs na conformação das centralidades urbanas. Para tal, mediu-se o número de viagens geradas especificamente por empreendimentos classificados como PGVs com relação às viagens totais dos subcentros identificados.

Com base nos dados analisados, sobre a influência dos PGVs na formação das centralidades, dos 15 subcentros analisados, 10 apresentaram números de viagens geradas por PGVs superiores a 60\%, corroborando a relação entre os PGVs e características de centralidade na área em que se inserem. Com relação aos usos e atividades que mais geram impactos na formação e consolidação de centralidades, em conformidade com os casos estudados, PGVs de usos institucionais e comerciais mostraram-se os mais relevantes na alteração dessa estrutura espacial urbana.

Como limitações do trabalho, o mesmo focou apenas na análise de PGVs não domiciliares. Entretanto, o estudo da Zona 504 demonstrou a necessidade de se considerarem os subcentros com uso domiciliar, abrindo uma nova frente de pesquisa, uma vez que se necessita investigar, mais detalhadamente, os PGVs residenciais, ou conjuntos desses PGVs, e seus impactos na estrutura espacial das cidades. Essa observação assume relevância ao questionar: (i) metodologias de identificação de subcentros que baseiam sua investigação apenas na variável número de empregos; (ii) movimentos de renovação de centros urbanos com a reocupação de edifícios (antes comerciais) para o uso domiciliar, assim como sobre qual seria o impacto dessa ocupação no contexto dos subcentros.
No contexto do planejamento urbano e de transportes, torna-se fundamental entender o processo de contribuição dos PGVs na conformação de centralidades, uma vez que a análise da estrutura espacial urbana de uma cidade, a partir da sua rede de centro e subcentros, pode contribuir, sobremaneira, para embasar diretrizes de ordenamento territorial.

Como estudos a serem desenvolvidos a partir do presente trabalho, sugere-se:

- Aplicar o procedimento proposto em outros subcentros localizados em cidades distintas, procurando avaliar se a relação encontrada neste trabalho repete-se em outros subcentros, assim como identificar e confirmar as atividades mais significativas para a formação e consolidação de centralidades;

- Investigar, mais detalhadamente, os PGVs residenciais, ou conjuntos desses PGVs, e seus impactos na estrutura espacial das cidades;

- Entender o processo de contribuição dos PGVs na conformação de centralidades, uma vez que, sendo os subcentros um dos tipos de nós da rede de transporte, estes podem contribuir para o planejamento de determinados nós, consolidando diretrizes de planejamento dos sistemas de transporte, com ênfase para o sistema de transporte público;

- Gerar estudos que analisem a acessibilidade nos PGVs, nos subcentros e nas demais áreas da cidade com destino a estes, permitindo a adoção de políticas para incentivar ou restringir determinados modos de deslocamento; e contribuir para incentivar, nesses locais, modos coletivos e não motorizados de transporte.

\section{AGRADECIMENTOS}

Erika Cristine Kneib, Paulo Cesar Marques da Silva e Licinio da Silva Portugal agradecem ao CNPq e FAPERJ pela apoio ao desenvolvimento da Rede Ibero-americana de Estudo em Pólos Geradores de Viagens.

\section{REFERÊNCIAS BIBLIOGRÁFICAS}

Aguilera, A. e Mignot, D. (2004) Urban sprawl, polycentrism and commuting. A comparison of seven french urban areas. Urban Public Economics Review. No. 001. Universidad de Santiago de Compostela. España.

Anderson, N. B. e Bogart, W. T. (2001) The structure of sprawl. Identifying and characterizing employment centers in policentric metropolitan areas. American Journal of Economics and Sociology. v. 60. N1.

Castells, M. (1983) A Questão Urbana. Rio de Janeiro: Paz e Terra.

CET (1982) Polos Geradores de Tráfego. Boletim Técnico No 32. Companhia de Engenharia de Tráfego. Prefeitura de São Paulo.

Cevero, R. (1996) Jobs-housing balance revisited: trends and impacts in the San Francisco Bay Area. Journal of the American Planning Association 62 (4), 492-511.

Correa, R. L. (1995) O espaço urbano. São Paulo. Editora Ática.

DENATRAN (2001) Manual de procedimentos para o tratamento de polos geradores de tráfego. Departamento Nacional de Trânsito. Brasília: DENATRAN/FGV.

Diesendorf, M. (2000) Urban Transportation in the 21st Century. Environmental Science \& Policy 3,11-13. 
Ewing, R. (1997) Is Los Angeles-style sprawl desirable? Journal of the American Planning Association 63 (1), 107-126.

França, A. (2004) Indicadores de desempenho espacial estudo de caso: a cidade de Cutitibanos - SC. Dissertação de M.Sc. Universidade Federal do Rio Grande do Sul.

Giuliano, G., Small, K. A. (1991) Subcenters in the Los Angeles Region. Regional Science and Urban Economics 21, 163-182.

Gordon, P. e Richardson, H. W. (1996) Beyond polycentricity: The dispersed metropolis, Los Angeles, 1970-1990. Journal of the American Planning Association 62 (3), p. 289.

Grando, L. (1986) A Interferência dos Polos Geradores de Tráfego no Sistema Viário: Análise e Contribuição Metodológica para Shoppings Centers. Dissertação de M. Sc. COPPE-UFRJ, Rio de Janeiro.

IBGE (2009) Amazonas, Manaus. Cidades @. Instituto Brasileiro de Geografia e Estatística. Disponível em: <www.ibge.gov.br>. Acesso em: maio 2010.

ITE (2001) Trip Generation Handbook. Institute of Transportation Engeneers. Washingtong DC.

ITE (2008) Trip Generation. An ITE Informational Report. Institute of Transportation Engeneers. Washingtong DC.

Kazerani, A. e Winter, S. (2009) Can Betweenness Centrality Explain Traffic Flow? 12th AGILE International Conference on Geographic Information Science 2009. Leibniz Universität Hannover, Germany.

Kneib, E. C. (2004) Caracterização de empreendimentos geradores de viagens: contribuição conceitual à análise de seus impactos no uso, ocupação e valorização do solo urbano. Dissertação de M.Sc. Transportes, Universidade de Brasília.

Kneib, E. C. (2008) Subcentros urbanos: contribuição conceitual e metodológica à sua definição e identificação para planejamento de transportes. Tese de D.Sc. Universidade de Brasília.

Kneib, E. C.; Taco, P. W. G; Silva, P. C. M. da S. (2009) Polos geradores de viagens e mobilidade: a evolução dos conceitos e da consideração dos impactos gerados. Revista dos Transportes Públicos, v. $121,65-80$.

Lefebvre, H. (2004) Evolução Urbana. Belo Horizonte. Editora UFMG.

Levinson, D. M. e Kumar, A., (1994) The rational locator: why travel times have remained stable. Journal of the American Planning Association 60 (3), 319-332.

McMillen, D. P. (2004) Employment densities, spatial correlation, and subcenters in large metropolitan areas. Journal of Regional Science 44, 225-243.

Ministério das Cidades (2004) Plano Diretor Participativo. Ministério das Cidades. Brasília.

Pan, Q. e Ma, L. (2006) Employment Subcenter Identification: A GISBased Method. Texas Southern University. Science and Urban Economics 21(2), 63-82.

Portugal, L. da S. e Goldner, L.G. (2003) Estudo de Polos Geradores de Tráfego e de seus impactos nos sistemas viários e de transportes. São Paulo, Edgard Blucher, 1a edição.

Prefeitura de Manaus, CEFTRU (2006) Relatório de Diagnóstico do Transporte Coletivo Urbano de Manaus - RTC/MAO. Prefeitura de Manaus e Centro de Formação de Recursos Humanos em Transportes, Universidade de Brasília.

Rede Ibero-Americana de Estudos de Polos Geradores de Viagens (2005) Relatório da $1^{a}$ Reunião de Trabalho. Universidade Federal do Rio de Janeiro. Disponível em: $<$ http://redpgv.coppe.ufrj.br/arquivos/1aReuniao_Relatorio_Abril _de_2005.pdf $>$.

REDPGV (2010) O que é um PGV? Rede Ibero-Americana de Estudo em Polos Geradores de Viagens. Disponível em: $<$ http://redpgv.coppe.ufrj.br>. Acesso em: maio 2010.

Rochefort, M. (1998) Redes e Sistemas: Ensinando sobre o Urbano e a Região. Hucitec. São Paulo.

Rodrigue, J. P. (2006) Transportation and Urban Form. In: The Geography of Transports Sistems. Routledge.

Schwanwn, T.; Dieleman, F. M.; Dijst, M. (2001) Travel behavior in Dutch monocentric and polycentric urban systems. Journal of Transportation Geography 9, 173-186.

Taaffe, E. J.; Gauthier, H. L; O'kelly, M. E. (1996) Geography of transportation. $2^{\text {a }}$. ed. Upper saddle river: Prentice Hall.

Villaça, F. (2001) Espaço intra-urbano. São Paulo, Studio Nobel. 